\begin{tabular}{|c|c|}
\hline$\sqrt{1} \bar{x}$ & Malaysian Journal of Social Sciences and Humanities (MJSSH) \\
\hline $\begin{array}{l}\text { Malaysian Journal of } \\
\text { Social Icciences and }\end{array}$ & Volume 5, Issue 7, July 2020 \\
\hline (MJ - SSH) & e-ISSN : 2504-8562 \\
\hline$=$ & $\begin{array}{l}\text { Journal home page: } \\
\text { www.msocialsciences.com }\end{array}$ \\
\hline
\end{tabular}

\title{
Voting Experiences of Visual Impaired Citizens During Polling Day in Malaysia
}

\author{
Bavani Ramayah', Rajini Kumar ${ }^{2}$ \\ 1Faculty of Science and Engineering, University of Nottingham, Malaysia \\ 2Faculty of Creative Industries, University Tunku Abdul Rahman (UTAR), Malaysia \\ Correspondence: Bawani Ramayah (bavani.r@nottingham.edu.my)
}

\begin{abstract}
Voting is a core responsibility of a citizen as every citizen has equal rights to cast his/her votes during polling day. However, individuals with disabilities encountered many challenges when it comes to voting. To address these issues, we conducted a study to explore the experiences of individuals with visual impairment during polling day of the General Election 2018 in Malaysia. The study has discovered that there are some significant issues encountered by individuals with visual impairment such as trust, privacy, facilities in polling station, limited guidance in polling station and mobility. In order to prevent these obstacles this research has suggested some solutions. The findings of this research will help the government and Electoral Commission to make elections more accessible for everyone in future especially for the visual impaired people
\end{abstract}

Keywords: accessibility, disability, general election, visual impairment, voting, polling

\section{Introduction}

The registered Person with Disabilities (PWD) at the Department of Social Welfare, Malaysia in 2017 were 453,258 persons (DOSM, 2018). However, people with vision impairment is the second largest group $(8.9 \%)$. Based on the Persons of Disabilities Act 2008 Malaysia, Persons with Disabilities (PWD) includes those who have long-term physical, mental, intellectual or sensory impairments such as visual impairment, hearing impairment or speech impairment that cause various barriers that may hinder them from effective participation in society. One of the barrier is voting process in an election (HO \& J.LIM., 2020). The voting process in an election is considered as a complex process for everyone that includes arriving to the poll station, getting voting number, understanding instruction given by poll worker, making selection on a ballot and casting the ballot. The whole process become more challenging for people who are having some disabilities especially for people with vision impairment.

\section{Various Voting Methods in Other Countries}

Some accessible voting methods were introduce upon the demands made by the people with vision impairment in various countries. In Malawi, The Malawians who are blind have requested Malawi Electoral Commission to make available tactile ballot guides (TBG) for them to cast their votes independently since they were not assisted in the past elections (GAATES, 2014). The request was granted and Malawi Electoral Commission decided to let the visually impaired to cast their votes 
independently by using tactile ballot although the electoral law allows a person with vision disability to bring someone from home to assist in voting. The similar method has been adopted in India and Ireland as the Braille ballot papers were provided for the visually impaired voters during the election (Sorcha, 2018; The HinduTimes, 2018). Ireland has introduced new ballot papers as decided case of Robbie Sinnott in the High Court. Robbie Sinnott initiated proceedings in 2016 against the Minister for the Environment, Community and Local Government and the State. Sinnott complained that he was being deprived of his right to a secret ballot because he had to ask a polling station presiding officer to complete his ballot paper. He ultimately won the case in April 2017(Sorcha, 2018).

On the other hand, another voting method was introduced in Japan since braille ballot paper is not effective enough for the visually impaired voters. Yahoo Japan created a website collaborated with screen-reader software to make the content audible and usable for the visually impaired people (Ryall, 2017). In Australia, the State Government has approved the use of VoteAssist, a computer-based application developed by the Western Australian Electoral Commission for its 2013 state election (Chris, 2013; Stephanie, 2018). The software used specially designed computer terminals, headphones and a numeric keypad to provide audio prompts to guide the elector through the voting process (Stephanie, 2018). It provides a secure, safe and independent method of voting that does not store votes electronically or remotely. In United States, touch screens and audio ballots are provided for the visually impaired voters during the election (Sandy, 2016). Countries such as India, Brazil, and Belgium have implemented and piloted electronic voting system (Kumar, 2011). Henceforth, in Malaysia, The Secretariat Election Commission have amended the rule of 19 Elections Regulations (Conduct of Election) 1981 (Amendment) 2012 that was gazetted on February 13, 2012. The amended election regulation allows the people with visual impairment to bring any individual whom they trust, in order to assist with the process of voting in the channel (The Secretariat Election Commission of Malaysia, 2013). If there are no relatives nominated, the Presiding Officer shall mark the voter's ballot in the manner that is instructed by the voter.

As discussed earlier, the various voting methods were implemented according to the issues and barriers encountered by voters in the respective countries and it is proven that the methods have promoted voting rates since it is acceptable to both sighted and visually impaired participants (Miura et al., 2016). Therefore, the main objective of this study is to explore the experiences and challenges faced by individuals with visual impairment during Parliamentary General Election 2018 in Malaysia and to suggest an accessible voting environment in future. In order to achieve our research objective, the open-ended questions were used to explore voters' experience with polling locations, transportation, poll worker's interactions and voters' confidence in those voting methods (Piner, 2011).

\section{Methodology}

An open-ended interview was conducted with visually-impaired people who had voted during the Parliamentary General Election recently (GE14) to investigate the challenges encountered by them on polling day. A total of six voters with visual impairment (low vision persons and legally blind persons) participated in this interview. There are five open ended questions. Table 1 shows the open-ended questions that were used during the interview session. The entire questions reflected the experience of the participants utilising the voting systems and facilities on the polling station during the voting process.

Table 1: Open-Ended Questions

\begin{tabular}{|c|c|}
\hline No & Question \\
\hline Q1 & $\begin{array}{l}\text { Malaysia had held a Parliamentary General Election recently (GE 14-2018). According } \\
\text { to your experiences during the previous General Elections, how the GE } 14 \text { has improved } \\
\text { in way more accessible to disable voters especially voters with visual impairment? }\end{array}$ \\
\hline Q2 & $\begin{array}{l}\text { Currently the voters with visual impairment have used the voting system in which they } \\
\text { are allowed to bring a family member or a person who they trust during the voting } \\
\text { process. What is your opinion on the efficiency and privacy of the system applied? }\end{array}$ \\
\hline
\end{tabular}


Q3 Is there any weakness against a disabilities-friendly environment at the polling station? Please provide some suggestions where the facilities or the staff can be improved.

Q4 There are some countries using Braille system during General Election and we have concerns about its advantages and disadvantages. However, we also have concern about the ratio of people with visual impairment in Malaysia who know Braille. What do you think about implementing an audio-based polling system as an alternative? Please give your opinion on both systems.

Q5 Please give your comments and share your experiences about other challenges faced during polling day.

\title{
Results
}

\section{Experiences and Suggestions shared by Voters with Visual Impairement}

The feedbacks shared by participants showed that they have encountered challenges during the General Election of Malaysia 2018. The major issues raised by participants were trust and privacy, facilities in polling station, assistance by staff on-duty in polling station, voting system and transportation. The following section discusses the responses and comments obtained from the study.

\section{Family member to assist Visually Impaired people during Voting Process}

Some of the participants showed their satisfaction towards the current voting system, which allows a family member, or a person whom they trust to assist them to vote, as Malaysia does not have an electronic voting system. However, visually impaired people are not satisfied with this method as they are uncertain of whether the assisting individual will be marking the ballot paper as instructed. Moreover, there may be differences between the political views of the two individuals, which could potentially lead to unwanted persuasion or coercion from the assisting individual on visually impaired voters. Thus, visually impaired voters also face trust and privacy issues in comparison to other incapacitated individuals during the elections. These issues stem from the fact that the visually impaired voters are not able to verify their vote or keep their political views private.

Below are the feedback summary shared by participants:

\begin{abstract}
"Allowing a sighted person whom we trust to assist us in the voting process makes it easier for us to participate in the election. However, we lose the confidentiality of our vote."
\end{abstract}

"It is a blind assumption to assume a family member is definitely someone we can trust. I used to be an Oppositionist, while my family supports the liberal. In this case, I would much prefer to rely on a trusted friend"

\section{Staff On-Duty in Polling Stations}

Briefing and training to the staff suggested, as some voters had an experience of being misled by staff in the polling station. An Election Commission (EC) helpline or special counter should also be created for enquiries by the voter with special needs. More wheel chairs should be provided in the polling station as it is always ran out of wheelchairs during the peak hours. Moreover, staff who is on-duty in polling stations should be well-trained with all the guidelines to avoid further confusion among voters.

\section{Alternative Options of Voting Method}

Based on the opinions of the participants, Braille is a friendlier way for the voters with visual impairment as it conserves the privacy and confidentiality of their votes. This also empowers the voters with visual impairment as they do not need to rely on others' help. However, it was said to be less practical with the fact that a significant number of visually-impaired people are Braille-illiterate. It 
could be an issue as it can be costly to print every ballot paper with Braille when not many voters with visual-impairment who can read and write braille well. Furthermore, stacking and transporting the ballot paper will also damage the dots.

Below are the feedback summary shared by participant:

"People with visual impairment can read simple tactile pattern of Braille but they might not be able to read the ballot paper especially with candidates' name and parties' logo in Braille. “

The respondents strongly suggested an audio-based system since it is a faster and more effective way than Braille system and the current voting system. It requires no knowledge on Braille for the voters especially with visual-impairment, and the speed of voting process is much faster than Braille voting system. Yet, as Malaysia is a multiracial country, voters from different races might only recognize their mother language, so the audio system needs to translate the information into an understandable language for the voters.

\section{Mobility Issues to Polling Station}

Transportation was one of the main issues encountered by participants on the Election Day, especially for the visually-impaired voters from suburb area. Some voters with visual impairments were allocated to a polling station which was far from their working place or home. In such scenario, they should be given priority and special help by allocating them to a nearer polling station and also assisting them on transportation. Moreover, some visually-impaired voters faced problem on receiving the information on the election candidates contesting in their constituency.

\section{Discussion and Recommendations}

The feedbacks obtained from this study shows that voters with visual impairement were more concerned about their trust and privacy related issues during the whole voting process. The Chief Executive of Malaysian Foundation of the Blind (MFB) suggested to introduce Braille template as the alternative way for the blind voter in Malaysia (MyMetro, 2018). This method has been implemented in many countries such as in Africa, India, and Ireland (Brand South Africa, 2009; Sorcha Pollak, 2018; The Hindu Times, 2018). Yahoo Japan created a website collaborated with screen-reader software to make the content audible and usable for the visually impaired people since they found that the braille ballot paper is not effective enough for the visually impaired voters in Japan (Julian, 2017).Similar voting method is applied in countries such as United State and Australia where visually impaired voters can cast a secret vote with help of computer-based application with audio prompt (Sandy, 2016; Stephanie, 2018). It provides a secure, safe and independent method of voting that does not store votes electronically or remotely.

As mentioned by participants during the interview session, improper guideline for the voters with special needs will cause further complication in their entire voting process. Voters who loss their vision completely in particular, rely on assistance and guideline provided in the polling station. Therefore a guidebook which is accessible for voters with special needs and also for staff who are on duty during polling day is very important. As being practised in the United Kingdom and United State, there is a guidebook that contains guidelines for staff where they need to make sure that they know how to handle voters with visual impairement and explain how to use the tactile template to the blind voters (Disability Rights Section, 2004; Electoral Commission, 2017).

Furthermore, facilities in polling station need to be given utmost importance during polling day. Wheelchairs, scribes for persons with visual disability to help them cast their votes, ramps and other facilities must be prepared at the polling station (The Hindu News, 2018). The polling station must be located at the ground floor so it will be more accessible not only for visually impaired people but also to other people with special needs. If people with special needs feel uncomfortable with the 
DOI: https://doi.org/10.47405/mjssh.v5i7.435

assigned polling station, they should be given an option to apply for an alternative polling station prior to the polling day (Department of Housing, Planning and Local Government, 2018).

\section{Conclusion and Future Work}

Seeing through the eyes of voters with visual impairement helps to unfold information about the challenges they have to go through during the polling day. Therefore, this research will provide insights for public, researchers, educators, law makers who want to have in-depth understanding of challenges faced by visually impaired users during polling day. The drawback on current voting process can be suppressed by having an effective voting methods and system together with detailed election guidebook. This will ensure and encourage civic consciousness among visually impaired people and also people with special needs by providing fundamental rights as citizen to vote. As a future work, further study will be carried out on accessible voting system that is suitable to be implemeted in Malaysia.

\section{Acknowledgements}

The authors would like to thank the participants who volunteered for this study, the Malaysian Blind Association (MAB), Malaysian Foundation for the Blind (MFB) and National Council for Blind, Malaysia (NCBM) for their tremendous supports.

\section{References}

Brand South Africa. (2009). Ballot papers now in Braille. Brand South Africa. Retrieved from https://www.brandsouthafrica.com/people-culture/democracy/ballot-160409

Chris, A. (2013). Western Australian Electoral Commission. Annual Reports 2011-12.. Retrieved from https://www.elections.wa.gov.au

Department of Housing, Planning and Local Government. (2018). Facilities for voters with disabilities. Retrieved from http://www.citizensinformation.ie/

Disability Rights Section. (2004). Ada Checklist for Polling Places. Retrieved from https://www.ada.gov/

DOSM, (2018). 'Social Statistics Bulletin Malaysia 2018', Department of Statistics Malaysia, Official Portal, 29 November. Available at: https://www.dosm.gov.my/

Electoral Commission. (2017). Handbook for polling station staff Supporting a UK Parliamentary election in Great Britain. Retrieved from https://www.electoralcommission.org.uk/

Global Alliance on Accessible Technologies and Environments (GAATES). (2014). Call to print Braille ballot papers. Retrieved October 24, 2018, from http://globalaccessibilitynews.com/

Ho, Y. \& Jeremy, L. (2020). Inclusive Electoral Reforms.

Ibrahim, S., Kamat, M., Salleh, M., \& Aziz, S. R. A. (2003). Secure E-voting with blind signature. In 4th National Conference on Telecommunication Technology, NCTT 2003 - Proceedings (pp. 193-197). https://doi.org/10.1109/NCTT.2003.1188334

Julian, R. (2017). Japan's visually impaired voters benefit from unique project. Dw Akademie. Retrieved from http://www.dw.com/

Kumar, S., \& Walia, E. (2011). Analysis of Electronic Voting System In Various Countries. International Journal on Computer Science and Engineering, 3(5), 1825-1830.

Miura, T., Kitagami, A., Fujinawa, Y., \& Nagoya, T. (2016). Accessibility, efficacy, and improvements in voting methodology for visually impaired persons using a web-based electronic ballot system (pp. 75-83). https://doi.org/10.1145/3014362.3014370

MyMetro. (2018). Perlu ada kertas undi Braille | Harian Metro. Metro. Retrieved from https://www.hmetro.com.my/

Piner, G. E., \& Byrne, M. D. (2011). The experience of accessible voting: Results of a survey among legally-blind users. Proceedings of the Human Factors and Ergonomics Society, 1686-1690. https://doi.org/10.1177/1071181311551351 
DOI: https://doi.org/10.47405/mjssh.v5i7.435

Royal National Institute of Blind People (RNIB). (2017). Blind and partially sighted people were denied the right to vote independently and in secret. Retrieved from https://www.rnib.org.uk/

Sandy, M. (2016). How do People Who Are Blind or Visually Impaired Vote. Retrieved from https://chicagolighthouse.org/sandys-view/people-blind-visually-impaired-vote/

Sorcha, P. (2018). Tactile ballot templates to facilitate visually impaired in voting. Retrieved October 24, 2018, from https://www.irishtimes.com/news/

Stephanie, R. (2018). Vision-impaired voters to have access to electronic voting at state election. In Daily News. Retrieved from https://indaily.com.au/news/

The Hindu Times. (2018). Polling booths to be disabled friendly. Retrieved from http://www.thehindu.com/news/national/karnataka/polling-booths-to-be-disabledfriendly/article23367996.ece

The Secretariat Election Commission of Malaysia. (2013). The EC's Clarifications On The Issues of The Electoral Roll And The Improvement of Electoral Process. Retrieved from http://aceproject.org/ero-en/regions/asia/MY/malaysia-electoral-commission-clarifications-on 